\title{
Arthritis and angioimmunoblastic lymphadenopathy
}

\author{
P. G. DAVIES AND J. N. FORDHAM \\ From the Departments of Rheumatology, Hackney Hospital, London E9, and Prince of Wales Hospital, \\ London N15
}

SUMMARY We report 2 contrasting cases of a seronegative polyarthritis associated with angioimmunoblastic lymphadenopathy (AILD). Both cases were nonerosive, with symmetrical involvement of the elbows, wrists, knees, and ankles. In one the arthritis appeared concurrently with the main systemic manifestations of AILD. The second presented with polyarthritis 18 months before the onset of AILD. This patient received azathioprine for 11 months before developing AILD, which raises the possibility of this drug being the causative agent.

Angioimmunoblastic lymphadenopathy (AILD) is a recently described lymphoproliferative disorder of unknown aetiology and pathogenesis. ${ }^{1-3}$ The typical clinical features are lymphadenopathy, hepatosplenomegaly, rash, and hypergammaglobulinaemia. Both arthralgia and arthritis have also been described in 18 cases $^{4-13}$ and appear to be less common but definite clinical features.

In most of the reported cases rheumatic features have not been well described. In some cases arthralgia alone has been mentioned, ${ }^{411}$ but in 11 cases arthritis has been a feature..$^{4-13}$ Five cases have been documented as being seronegative $e^{4-913}$ and 3 as being seropositive. ${ }^{4610}$ Two of the seropositive patients appeared to have had coexistent rheumatoid arthritis. In one case ${ }^{12}$ with bilateral carpal tunnel syndrome and polyarthropathy, synovial histology was obtained which showed a mononuclear infiltrate.

We describe 2 contrasting cases. In the first case the arthritis appeared with the main systemic manifestations of AILD, while in the second case the arthritis preceded the onset of AILD by 18 months.

\section{Case reports}

CASE 1

A 50-year-old Caucasian woman presented in August 1980 with a one-week history of fever, sore throat, swollen glands, and an itchy rash over her arms and trunk, which later spread to involve her palms, lower legs, feet, and face.

Her symptoms continued, and in early September she was admitted to hospital following the onset of a

Acepted for publication 7 October 1982.

Correspondence to Dr P. G. Davies, Bone and Joint Research Unit, The London Hospital Medical College, London E1 2AD. polyarthritis involving her knees, ankles, elbows, and wrists. Examination revealed hepatosplenomegaly, generalised lymphadenopathy, and a maculopapular rash. There was active synovitis of the metacarpophalangeal, wrist, knee, and ankle joints. She ran an intermittent fever of up to $38.5^{\circ} \mathrm{C}$.

Haemoglobin was $13.1 \mathrm{~g} / \mathrm{dl}$, leucocytes $9.3 \times 10^{9} / 1$ ( $71 \%$ neutrophils, $12 \%$ lymphocytes, and $9 \%$ eosinophils). ESR $58 \mathrm{~mm} / \mathrm{h}$. Electrolytes, urea, and liver function tests were normal. Serum albumin was $35 \mathrm{~g} / 1$ and globulin $40 \mathrm{~g} / \mathrm{l}$. Protein electrophoresis showed a diffuse increase in gammaglobulin. Latex test for rheumatoid factor and antinuclear antibody test (ANA) were negative. C3 was normal. Chest and joint $x$-rays were normal except for mild degenerative changes in the right knee. Aspiration of the left knee revealed clear, straw coloured fluid with a moderate number of leucocytes, of which $88 \%$ were polymorphonuclear. Culture was sterile and no crystals were seen.

Lymph node biopsy from the right groin showed the features of angioimmunoblastic lymphadenopathy (Fig. 1). The normal lymph node architecture was almost entirely replaced by a proliferation of small blood vessels and a polymorphic infiltrate, including immunoblasts, plasma cells, and eosinophils with frequent mitotic figures.

In early October she was transferred to the oncology unit at St Bartholomew's Hospital. Examination at that time revealed ankle oedema and crackles in the left lower zone of the chest. Computed tomography showed mediastinal and abdominal para-aortic lymphadenopathy. There was diffuse lung shadowing with small bilateral pleural effusions and hepatosplenomegaly. 


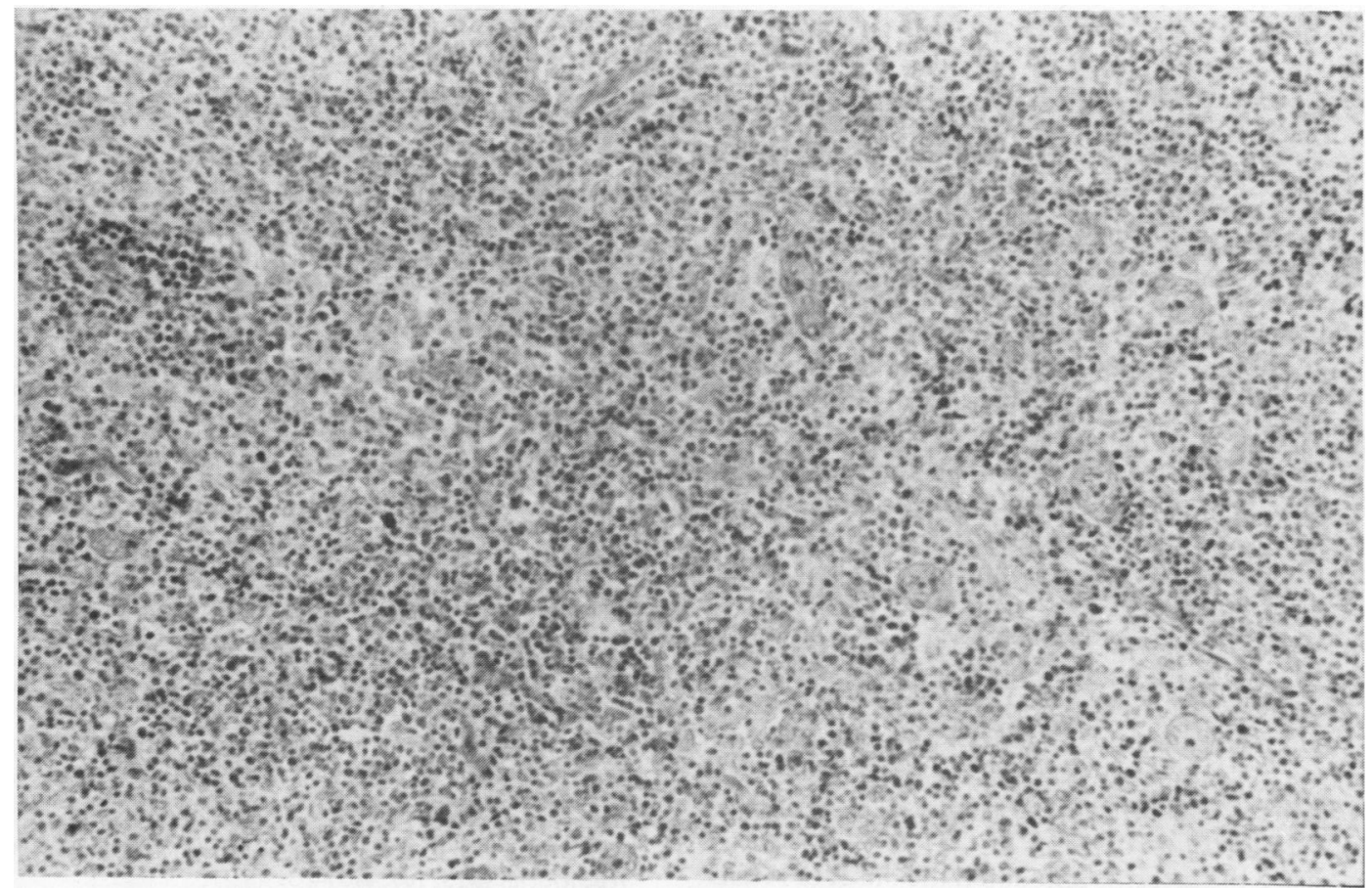

Fig. 1 Lymph node showing proliferation of small blood vessels and a polymorphic infiltrate including immunoblasts, plasma cells, and eosinophils. ( $H$ and $E, \times 200$ ).

A regimen of mustine, vinblastine, procarbazine, and prednisolone at 6-week intervals was begun. After 6 cycles she went into clinical remission, with regression of her lymphadenopathy, hepatosplenomegaly, and arthritis, and this has been maintained to date (August 1982).

\section{CASE 2}

A 73-year-old woman presented in December 1977 with a 3-month history of pain and stiffness affecting her wrists, shoulders, hips, and ankles. Examination revealed active synovitis of her shoulders, elbows, wrists, left knee, and both ankles. ESR was $129 \mathrm{~mm} / \mathrm{h}$ and haemoglobin was $9 \cdot 1 \mathrm{~g} / \mathrm{dl}$. The latex test for rheumatoid factor and ANA test were both negative. $X$-rays showed no erosions.

She made little improvement on either aspirin or naproxen, and she was subsequently given azathioprine $100 \mathrm{mg}$ daily. On this drug her joint symptoms improved, her ESR fell to $52 \mathrm{~mm} / \mathrm{h}$, and her haemoglobin rose to $11.5 \mathrm{~g} / \mathrm{dl}$.

In February 1979 she complained of anorexia and lethargy. She was found to have palpable left axillary and supraclavicular nodes with hepatosplenomegaly. Leg oedema and ascites were also noted. Haemoglo- bin was $9 \cdot 1 \mathrm{~g} / \mathrm{dl}$, white cell count $8.9 \times 10^{9 / 1}(73 \%$ neutrophils, $13 \%$ lymphocytes, $4 \%$ monocytes, and $6 \%$ plasma cells). The platelet count was $57 \times 10^{\%} / 1$ and reticulocytes $4 \%$. The Coombs test was positive. The latex test for rheumatoid factor and ANA were again negative. Her blood urea had risen to $32 \cdot 8$ $\mathrm{mmol} / \mathrm{l}$. Serum albumin was $25 \mathrm{~g} / \mathrm{l}$ and globulin $65 \mathrm{~g} / \mathrm{l}$. Fibrin degradation products were elevated at 160 $\mathrm{mg} / \mathrm{l}$.

A diagnosis of disseminated intravascular coagulation was made and her haemoglobin continued to fall to $7 \mathrm{~g} / \mathrm{dl}$. She remained ill with an intermittent fever and lymphadenopathy. A lymph node biopsy was performed, and the histology showed the features of angioimmunoblastic lymphadenopathy with replacement of normal lymph node architecture with immunoblasts, plasma cells, and arborising blood vessels.

She was treated with prednisolone $20 \mathrm{mg}$ t.d.s. and transfused with 4 pints $(2 \cdot 31)$ of blood in all. Despite this there was no sustained increase in haemoglobin or platelets. The oedema became more pronounced and she became weaker over the following few months; she finally developed bronchopneumonia and died in April 1979. 


\section{Discussion}

These 2 cases demonstrate that AILD, although rare, has a place in the differential diagnosis of seronegative polyarthritis, though seropositive cases have also been described..$^{4610}$ AILD shares many features with systemic lupus erythematosus (SLE) and adult-onset Still's disease. The rarity of a positive ANA in this disorder allows differentiation from systemic lupus erythematosus. ${ }^{12}{ }^{13}$ However, a definite diagnosis can be made only from the histological appearance of a lymph node or skin biopsy. ${ }^{14}$ The characteristic histological features are: effacement of lymph node architecture; proliferation of arborising small vessels; polymorphic cellular infiltrate with immunoblasts, plasma cells, lymphocytes, eosinophils, and histiocytes; and the presence of amorphous acidophilic interstitial material. ${ }^{23}$

In case 1 the arthritis appeared in association with the other major features of this disorder. Analysis of the reported cases in which arthritis and AILD have been describe $\mathrm{d}^{4-13}$ shows that this is the usual time for the arthritis to appear. It is likely, because of this timing, that the arthritis in these cases is a true clinical manifestation of AILD.

In case 2 the arthritis antedated the onset of AILD by 18 months. It is interesting to speculate whether this arthritis was separate from AILD or a prodroma of AILD. Three cases of AILD have previously been reported in which the arthritis appeared before the major manifestations of this disorder. Flandrin, ${ }^{6}$ in a series of patients with AILD, had one patient with a past history of rheumatoid arthritis. Goudsmit et al. ${ }^{7}$ described a patient who developed a rash and arthritis 4 months before the main features of AILD developed. And Rothwell et al. ${ }^{13}$ have recently reported a well documented case in which a seronegative polyarthritis developed 4 months before the apparent onset of AILD, though a rash appeared 2 months after the arthritis. In these last 2 cases it would seem probable that the arthritis was a prodroma of AILD. The gap between the arthritis and the onset of AILD was considerably longer than 4 months in our second case, but it would seem likely that the arthritis and AILD are in some way related.

The aetiology and pathogenesis of AILD are unclear, but 2 pathogenetic mechanisms have been proposed. Frizzera et al. ${ }^{2}$ have sugested that it is an autoimmune disorder with defective $T$ cell regulatory function, which may predispose to an abnormal pro- liferative and autoaggresive reaction of B cells. However, Lukes and Tindle ${ }^{3}$ labelled it a hyperimmune entity with B cell proliferation and proposed that it may be triggered by a hypersensitivity reaction to drugs.

In case 2 AILD followed 11 months of treatment with azathioprine. Although there are no previous reports of AILD following azathioprine therapy, this possible association needs consideration in view of this drug's oncogenic potential.

We thank Dr D. S. Tunstall Pedoe for permission to report the first case and Professor A. G. Stansfeld for his report on the lymph node histology of the first case.

\section{References}

1 Lukes $\mathbf{R ~ J}$, Tindle B $\mathbf{H}$. Workshop on classification of non-Hodgkin's lymphomas. University of Chicago, 25-29 June 1973.

2 Frizzera G, Moran E M, Rappaport H. Angio-immunoblastic lymphadenopathy: diagnosis and clinical course. Am J Med 1975; 59: 1-18.

3 Lukes R J, Tindle B H. Immunoblastic lymphadenopathy: a hyperimmune entity resembling Hodgkin's disease. $N$ Engl $J$ Med 1975; 292: 1-8.

4 Radaszkiewicz T, Lennert $K$. Lymphogranulomatosis $X$. Klinisches Bild, Therapie und Prognose. Disch Med Wochenschr 1975; 100: 1157-63.

5 Bensa J C, Faure J, Martin H, Sotto J J, Schaerer R. Levamisole in angioimmunoblastic lymphadenopathy. Lancet 1976; i: 1081.

6 Flandrin G. Adenopathies angioimmunoblastiques avec anémie autoimmune et hyperimmunoglobulinémie polyclonale. Nouv Press Med 1976; 5: 1521-4.

7 Goudsmit R, Van Heerde P, Jobsis A C, Kr A E G, Borne V D, Somers R. (Angio) Immunoblastic lymphadenopathy: a presentation of 5 cases. Neth J Med 1976; 19: 171-84.

8 Pruzanski W, Sutton D M C, Pantalony D. Angio-immunoblastic lymphadenopathy: an immunochemical study. Clin Immunol Immunopathol 1976; 6: 62-76.

9 Rochant H, Reyes F, Vernant J-P, et al. Aspects évolutifs de la lymphadénopathic anti-immunoblastique. Ann Med Interne (Paris) 1976; 127: 857-61.

10 Rudders $\mathbf{R}$ A, DeLillis $\mathbf{R}$. Immunoblastic lymphadenopathy. Am J Clin Pathol 1977; 68: 518-21.

11 Dujardin P, Audoly P, Cassuto J-P, Kermarec J. Les lymphadénopathies anti-immunoblastiques avec dysprotéinémie. Sem Hop Paris 1977; 53: 1425-9.

12 Cullen M H, Stansfeld A G, Oliver R T D, Lister T A, Malpas J S. Antio-immunoblastic lymphadenopathy: report of 10 cases and review of literature. $Q J$ Med 1979; 48: 151-77.

13 Rothwell R S, Mant M J, Davis P. Angio-immunoblastic lymphadenopathy associated with polyarthritis. Ann Rheum Dis 1980; 39: 406-9.

14 Bernengo M G, Levi L, Zina G. Skin lesions in angioimmunoblastic lymphadenopathy: histological and immunological studies. Br J Dermatol 1981; 104: 131-9. 